\title{
Effects of progesterone administration on infarct volume and functional deficits following permanent focal cerebral ischemia in rats
}

\author{
Tauheed Ishrat, Ph.D., Iqbal Sayeed, Ph.D., Fahim Atif, Ph.D., and Donald G. Stein, Ph.D. \\ Department of Emergency Medicine, Emory University School of Medicine, Atlanta, GA 30322, USA
}

\begin{abstract}
Recent experimental evidence indicates that progesterone (PROG) protects against various models of brain injury, including ischemic stroke. Most human studies of pharmacologic treatments for acute cerebral stroke have failed despite initial success in animal models. To simulate better the typical human stroke without reperfusion, the present study was conducted to examine the efficacy of PROG on infarct volume and functional outcome in a permanent model of stroke, using direct cauterization of the middle cerebral artery (MCA). Twenty-four male adult Sprague-Dawley rats underwent pMCAO by electro-coagulation and sham operation. After induction of permanent MCA occlusion (pMCAO), the rats received an initial intraperitoneal injection of PROG $(8 \mathrm{mg} / \mathrm{kg})$ or vehicle at $1 \mathrm{~h}$ post-occlusion followed by subcutaneous injections at 6, 24 and $48 \mathrm{~h}$. Functional deficits were tested on the rotarod and grip strength meter at 24, 48 and $72 \mathrm{~h}$ after pMCAO. The rats were killed $72 \mathrm{~h}$ after surgery and isolated brain was sectioned into coronal slices and stained with 2, 3, 5-

triphenyltetrazolium chloride (TTC). PROG-treated rats showed a substantial reduction (54.05\%) in the volume of the infarct (\% contralateral hemisphere) compared to vehicle controls. In addition there was a significant improvement in ability to remain on an accelerating rotarod and increased grip strength observed in the pMCAO rats treated with PROG compared to vehicle. Taken together, these data indicate that PROG is beneficial in one of the best-characterized models of stroke, and may warrant further testing in future clinical trials for human stroke.
\end{abstract}

\section{Keywords}

Progesterone; Brain damage; Permanent MCAO; Functional recovery; Infarct volume

\section{Introduction}

Stroke, an obstruction of blood flow in a major cerebral vessel, can cause permanent neurological damage, an area of infarcted tissue, severe functional impairments and death if not managed quickly (Hankey, 1999; Muntner et al., 2002). It is the second most frequent cause of death world-wide and the third leading cause of adult disability in the United States (Feigin, 2005). Currently, treatment options for stroke are limited, and many promising drugs have failed in human clinical trials due to intolerable side effects or therapeutic limitations. These

\footnotetext{
* Address for reprints and correspondence: Department of Emergency Medicine, Brain Research Laboratory, 1365B Clifton Road NE, Emory University, Atlanta, GA 30322, USA, Phone: (404) 712-2540, Fax: (404) 727-2388, donald.stein@emory.edu.

Publisher's Disclaimer: This is a PDF file of an unedited manuscript that has been accepted for publication. As a service to our customers we are providing this early version of the manuscript. The manuscript will undergo copyediting, typesetting, and review of the resulting proof before it is published in its final citable form. Please note that during the production process errors may be discovered which could affect the content, and all legal disclaimers that apply to the journal pertain.
} 
failures are to some extent attributable to approaches that did not conform to Stroke Therapy Academic Industry Roundtable (STAIR) guidelines, notably the lack of appropriate preclinical models. A safe and effective therapeutic strategy which can block or reduce the many harmful effects of ischemia-including excitotoxicity, oxidative stress, inflammation apoptosis, necrosis and acidosis (Danton and Dietrich, 2003; Mergenthaler et al., 2004)—is urgently needed.

A large body of evidence now suggests that the steroid hormone progesterone (PROG) has pharmacotherapeutic effects in several experimental injury models of stroke and trauma (reviewed by Stein and Hurn, in press). The neuroprotective efficacy of PROG in functional and morphological recovery has been confirmed both permanent and transient stroke models by our recent studies (Sayeed et al., 2006; 2007) and previous studies of others (Betz and Coester, 1990; Jiang et al., 1996; Chen et al., 1999; Murphy et al., 2002; Gibson and Murphy, 2004; Gibson et al., 2005). In addition to animal studies, two recent randomized, double-blind, placebo-controlled clinical trials using 3 or 5 days of intravenous PROG to treat patients with moderate to severe traumatic brain injury (TBI) demonstrated both safety and efficacy compared to patients given standard of care treatment plus placebo (Wright et al., 2007; Xiao et al., 2008). In the Wright, et al. trial, the severely injured patients given PROG had almost a $60 \%$ reduction in mortality and those diagnosed with 'moderate' brain injury had a significantly better functional outcome at 30 days after injury. Xiao and colleagues essentially confirmed these findings while also reporting functional improvements extending out to 6 months postinjury. Whether PROG would be beneficial in the clinical treatment of stroke has not yet been investigated in clinical trial.

Permanent or thromboembolic occlusion of cerebral arteries, especially middle cerebral artery occlusion (MCAO), is the commonest type of focal stroke in humans (Delcker et al., 1993; Hacke et al., 1996). For this reason, although its recommendations are still controversial, STAIR endorses the testing of agents in permanent models of ischemia to simulate better the typical human stroke without reperfusion (Fisher, 2003). More recently Stem cell Therapeutics as an Emerging Paradigm in Stroke (STEPS) recommended that it is imperative for translational research that the therapeutic agent be tested in clinically relevant multiple models of stroke, in two species, in both genders and in multiple laboratories (Borlongan et al., 2008). Permanent MCAO (pMCAO) with intraluminal thread technique is a widely used animal model of stroke. However, it has an important drawback: insertion of the thread leads to obstruction of the hypothalamic artery and thus to hyperthermia, which in turn increases infarct volume, worsens functional outcome (Zhao et al., 1994; Reglodi et al., 2000), and confounds drug evaluation (Memezawa et al., 1995). In addition, this model shows variability in infarct volumes and higher mortality rates (Kitagawa et al., 1998). In contrast, direct 'ligation' (cauterization) of the MCA in rats as developed by Tamura et al. (1981) has become the most reproducible and suitable model for approximating the pathology and symptoms of human stroke (Yamamoto et al., 1988; Hunter et al., 1998).

Most studies of PROG as a neuroprotective agent in stroke have been done with intraluminal MCAO models. The first study, published almost twenty years ago, examined PROG as a neuroprotective agent against brain edema in permanent focal stroke in rat by direct ligation of the MCA (Betz and Coester 1990). In the present study, we evaluated the effect of PROG on infarct attenuation and functional outcomes following direct permanent ligation of the MCA. Our results support the efficacy of post-administration of PROG in reducing infarct volume and improving functional outcome following cerebral ischemia. 


\section{Results}

\subsection{Physiological variables}

Physiological variables ( $\mathrm{SpO} 2$, heartbeat, body temperature) were measured at $10 \mathrm{~min}$ before and $90 \mathrm{~min}$ after cerebral ischemia. There were no significant differences $(\mathrm{P}<0.05)$ in physiological parameters among the sham-operated, pMCAO and pMCAO + PROG-treated groups (Table 1).

\subsection{Effect of PROG on infarct volume after pMCAO}

Figure 1 illustrates the effects of PROG on infarct volume (expressed as percent of intact contralateral structure). Figure 1A shows representative brain slices stained with TTC $72 \mathrm{~h}$ after pMCAO in vehicle-treated and PROG-treated rats. Figure 1B shows the distribution of percent area of infarct in serial brain sections stained with TTC $72 \mathrm{~h}$ after pMCAO in vehicletreated and PROG-treated rats. PROG administration significantly $(\mathrm{P}<0.05)$ reduced the total infarct volumes after pMCAO in the PROG-treated compared with vehicle-treated rats (20.11 \pm 3.1 vs. $9.24 \pm 2.96$, respectively).

\subsection{Effect of PROG on functional outcome after pMCAO}

2.3.1 Rotarod test-Time spent on the rotarod is expressed as a percentage of pre-surgery control value. A repeated measures ANOVA on latency to remain on the rotarod showed significant group $\left(\mathrm{F}_{(2,63)}=17.34, \mathrm{p}<0.05\right)$ and time $\left(\mathrm{F}_{(3,63)}=42.22, \mathrm{p}<0.05\right)$ effects. The rotarod tests showed significant $(\mathrm{P}<0.05)$ deficits in motor performance (time spent on the rotarod) in pMCAO-plus-vehicle-treated rats $(45.77 \pm 12.42,59.09 \pm 14.24,64.26 \pm 12.70$ at 24,48 , and $72 \mathrm{~h}$ post-occlusion, respectively) at all time points compared to shams ( $86.10 \pm$ $18.34,91.12 \pm 8.66,97.33 \pm 13.90$ at 24,48 , and $72 \mathrm{~h}$ post-occlusion, respectively. Repeated treatments with PROG after pMCAO significantly $(\mathrm{P}<0.05)$ improved the ability to remain on the rotarod $(68.46 \pm 15.11,77.34 \pm 17.11,86.62 \pm 18.46$ at 24,48 , and $72 \mathrm{~h}$ post-occlusion, respectively) at all time points (Fig. 2).

2.3.2 Grip-strength test-Treatments with PROG improved grip-strength score (in Newtons) resulting from pMCAO (Fig 3). There was no difference in the grip-strength score before surgery in any of the groups $(10.11 \pm 0.46 \mathrm{~N}, 9.9 \pm 0.24 \mathrm{~N}, 10.12 \pm 0.29 \mathrm{~N}$ in sham, pMCAO + vehicle, pMCAO + PROG, respectively). A repeated measures ANOVA on grip strength showed significant group $\left(\mathrm{F}_{(2,63)}=44.07, \mathrm{p}<0.05\right)$ and time $\left(\mathrm{F}_{(3,63)}=22.38, \mathrm{p}<0.05\right)$ effects. Grip-strength was decreased significantly $(\mathrm{P}<0.05)$ in rats subjected to pMCAO $(6.17$ $\pm 0.81 \mathrm{~N}, 6.80 \pm 0.78 \mathrm{~N}, 7.48 \pm 0.92 \mathrm{~N}$ at 24,48 , and $72 \mathrm{~h}$ post-occlusion, respectively) at all time points as compared to shams $(9.04 \pm 0.35 \mathrm{~N}, 9.12 \pm 0.78 \mathrm{~N}, 9.70 \pm 0.41 \mathrm{~N}$ at 24,48 , and $72 \mathrm{~h}$ post-surgery, respectively), but was significantly $(\mathrm{P}<0.05)$ improved with the repeated treatment with PROG $(7.77 \pm 0.76 \mathrm{~N}, 8.16 \pm 1.0 \mathrm{~N}, 9.11 \pm 0.54 \mathrm{~N}$ at 24,48 , and $72 \mathrm{~h}$ postsurgery, respectively).

\section{Discussion}

We show that a short course of post-injury treatment with PROG reduces cortical infarct volume and leads to an attenuation of the deficits in accelerating rotarod and grip strength testing after $72 \mathrm{~h}$ of pMCAO in rats. This neuroprotection with PROG in a cerebral ischemic injury model is consistent with our previous reports (Sayeed et al., 2006; 2007) and those of others (Betz and Coester, 1990; Jiang et al., 1996; Chen et al., 1999; Murphy et al., 2002; Gibson and Murphy, 2004; Gibson et al., 2005). A recent study by Aggarwal et al. (2008) also demonstrated neuroprotective efficacy of PROG following partial global ischemia in mice. 
In the present study the $8 \mathrm{mg} / \mathrm{kg}$ doses selected were based on previous findings showing the maximal effectiveness of PROG in the treatment of brain injury (Jiang, et al., 1996; Chen, et al., 1999; Kumon, et al., 2000; Goss, et al., 2003; Djebaili, et al., 2004). PROG administered at a dose of $8 \mathrm{mg} / \mathrm{kg}$, has been shown to be effective in reducing infarct volume and functional deficits in mice following MCAO (Gibson and Murphy, 2004). In rats, a dose of $8 \mathrm{mg} / \mathrm{kg}$ reduces lesion volume (Chen, et al. 1999; Kumon, et al., 2000), while lower (4 mg/kg) or higher doses $(32 \mathrm{mg} / \mathrm{kg}$ ) failed to have the same effect (Chen, et al., 1999) following cerebral ischemia. In our studies, it was considered more relevant to administer PROG after, rather than before, the behavior testing because of PROG's known sedative, anxiolytic, and anesthetic activity (Merryman, et al., 1959; Bixo and Backstrom 1990; Bitran, et al., 1995; Reddy, and Kulkarni, 1997; Djebaili, et al., 2004).

In virtually all cases, stroke is likely to induce death and/or dysfunction of brain cells, which then cause neurological impairments that depend on the volume and location of the ischemic brain area. Although important from an experimental perspective, lesion volume analysis by itself gives little indication of how profoundly affected an individual will be after stroke (Wahl et al., 1992; Hattori et al., 2000; Reglodi et al., 2003). In our study, treatment with PROG significantly reduced the infarct volume following pMCAO in rats. Overall, we found that the average total volume of infarction was reduced by $54.05 \%$ compared to the vehicle-treated group. These data corroborate our previous finding that PROG attenuates infarct volume in a transient and permanent suture rat model of stroke (Sayeed et al., 2006). Other studies have demonstrated PROG to be neuroprotective following global ischemia in cats (Gonzalez-Vidal et al., 1998; Cervantes et al., 2002) and focal ischemia in rats (Jiang et al., 1996; Chen et al., 1999; Murphy et al., 2002; Gibson and Murphy, 2004; Gibson et al., 2005). However, in one report Schiff and colleagues failed to observe any benefit of PROG treatment after brain injury in rats (Gilmer et al., 2008).

Muscle weakness or motor impairment is a common complaint after stroke in humans. So it is important for the pathophysiological study and development of drug therapies for stroke to use appropriate behavioral testing in conjunction with histological measurement (Bederson et al., 1986; Corbett and Nurse, 1998). In this study, we used accelerating rotarod and grip strength to evaluate the effect of PROG on behavioral outcome. Previous studies have shown that PROG improved deficits on the Zea Longa's neurological outcome measurement scale (Jiang et al., 1996; Chen et al., 1999; Kumon et al., 2000), rotarod performance and somatosensory neglect following transient (Chen et al., 1999) and permanent (Gibson and Murphy, 2004; Sayeed et al., 2007) MCAO. Consistent with the earlier observations, we found that behavioral deficits caused by pMCAO were significantly improved by PROG treatment at 24,48 , and $72 \mathrm{~h}$ after the surgery. The degree of improvement was substantial (approximately return to normal functioning) at $72 \mathrm{~h}$ post-occlusion.

The mechanism(s) of action by which PROG provides neuroprotection against infarction volume and functional benefits to rats that have undergone direct surgical MCAO are not completely known. PROG readily crosses the BBB and therefore reperfusion is not required to achieve adequate penetration to observe efficacy in a permanent model of ischemia. This is particularly relevant clinically since the majority of human stroke victims suffer from permanent occlusion (Hacke et al., 1996; Kassem-Moussa and Graffagnino 2002). Increasing evidence suggests that multiple deleterious pathological events may contribute to ischemic injury, such as excitotoxicity, oxidative stress, inflammation apoptosis, and necrosis (Danton and Dietrich, 2003; Mergenthaler et al., 2004). Because it is a pleiotropic agent it is likely that PROG acts by a combination of intranuclear and membrane mechanisms. PROG exerts its action primarily through the intracellular membrane-bound PROG receptor by inhibiting NMDAr-Ca2+ influx and activation of PR-mediated Src-ERK signaling pathways (Luconi et al., 1998; Cai et al., 2008). A number of studies have shown the multiple pathways by which 
PROG may exert its action in experimental brain injury, including its potentiating effect on GABA inhibition and attenuation of excitatory amino acid responsiveness, amplification of adenosine's inhibitory action on cerebral cortical neuronal activity, anti-apoptotic and antioxidant action, reduction of brain edema, and action as a free radical scavenger (Majewska, 1992; Roof, et al., 1997; He et al., 2004; Smith and Woolley, 2004; Djebaili et al., 2005; Gibson et al., 2005; Mani, 2006).

Brain edema accounts for much of the morbidity and mortality following stroke. PROG has consistently been shown to reduce edema both following TBI (Roof e al., 1993; Wright et al., 2001; Guo, et al., 2006) and permanent ischemia (Betz and Coester $1990 \mathrm{a}$ and b). Our recent results suggest that PROG modulates expression of AQP4 (Guo et al., 2006), a water channel protein shown to be critically involved in the formation and resolution of brain edema following ischemic brain injury (Frydenlund et al., 2006). Other mechanisms for the hormone's pleiotropic actions in enhancing neuronal sparing and repair after various kinds of brain injury have been reviewed elsewhere (Stein, 2008; Stein and Hurn, 2008). Recently, Cutler et al. (2007), found that in a rat model of TBI, acute PROG treatment helped to reduce inflammatory factors such as COX-2, IL-6 and NFkappaB at various time points after the injury. Since the stroke model also induces edema, it is likely that post-stroke administration of PROG would have similar benefits. Furthermore our laboratory has also shown (Vanlandingham, et al., 2007) that after a brain injury treatment with PROG increases the expression of CD-55, a cell surface protein which has the capacity to reduce complement factor convertases that trigger the inflammatory cascade capable of causing secondary neuronal loss. Since the enantiomer of PROG can also reduce edema (Vanlandingham et al., 2006), it is likely that some of the mechanisms of action do not require the activation of the intranuclear PROG receptor, but further work is needed to determine exactly how the reparative process unfolds.

In conclusion, PROG treatment significantly reduced infarct volume and improved functional deficits in a clinically relevant model of stroke and continues to show pre-clinical promise as a potential therapeutic strategy for stroke patients. Further investigations are needed to evaluate time-response mechanisms of action of PROG in an experimental, permanent stroke model.

\section{Experimental procedures}

\subsection{Animals and treatment regimen}

Twenty-four adult male Sprague-Dawley rats (300 to $340 \mathrm{~g}$; Charles River Laboratories, Wilmington, MA, USA) were used according to procedures approved by the Institutional Animal Care and Use Committee, Emory University, Atlanta, GA, USA (protocol 151-2005). The rats were quarantined for at least 7 days before the experiment. The animals were housed in individual cages in a room maintained at $21-25^{\circ} \mathrm{C}, 45-50 \%$ humidity and 12 -h light/dark cycle with free access to pellet chow and water.

The animals were separated into three groups of eight rats each. Group I: sham-operated vehicle-treated control (S); group II: pMCAO and vehicle-treated stroke (pMCAO); group III: $\mathrm{pMCAO}$ and PROG $(8 \mathrm{mg} / \mathrm{kg})$ (pMCAO + PROG). Consistent with previous research, PROG (P-0130; Sigma-Aldrich Co., St. Louis, MO, USA) was dissolved in 22.5\% 2-hydroxypropylb-cyclodextrin and given in a dose of $8 \mathrm{mg} / \mathrm{kg}$ by intraperitoneal injection $1 \mathrm{~h}$ post-occlusion to ensure more rapid absorption following injury. Additional injections of $8 \mathrm{mg} / \mathrm{kg}$ were administered subcutaneously 6,24 , and 48 h post-MCAO. PROG was administered after performing the behavior testing. The PROG dose used in this experiment was determined from previous studies showing that this amount provided the maximal protective effects in the treatment of different types of brain injury (Jiang et al., 1996; Chen et al., 1999; Kumon et al., 2000; Goss, et al., 2003; Djebaili, et al., 2005; Sayeed et al., 2006; 2007). 


\subsection{Induction of permanent focal cerebral ischemia}

For pMCAO in rats, isoflurane anesthesia was induced by $5 \%$ and maintained with $1.5-2 \%$ during surgery, in 2:1 nitrous oxide and oxygen. The original technique as described by Tamura et al. (1981) and Yamamoto et al. (1988) was used, with minor modifications, in our experiments to produce consistency in the ischemic injury. In brief, a ventral midline incision was made for exposure of both common carotid arteries (CCA). The contralateral right CCA was permanently ligated using a 3/0 silk suture. The ipsilateral (left) CCA was temporarily occluded for 90 min using a Mayfield micro-aneurysm clip just after the permanent occlusion of the MCA. A vertical incision was made midway between the left orbit and the left external auditory canal. After anterior and downward retraction of the musculature, the zygomatic bone was left intact, and the pterygoid muscles and mandibular nerve were retracted to expose the ventral surface of the skull. Under an operating microscope, the bone around the foramen ovale was burnished (2-3 mm) away to expose the MCA, and the craniectomy was extended dorsally up to the first major branch of the MCA. The dura was opened with a bent 26-gauge needle, the arachnoid membrane was gently removed and the MCA cauterized and cut permanently to prevent recanalization with a bipolar electrocauterizer without damaging the brain surface. The site of the occlusion is midway between the inferior cerebral vein and olfactory tract. The rats were allowed to recover from anesthesia on the heating pad and then returned to their home cages after full recovery from anesthesia. Sham-operated rats were subjected only to exposure of the MCA without coagulation. Anesthesia duration was similar in all groups.

Temperature was monitored and maintained $\left(37 \pm 2^{\circ} \mathrm{C}\right)$ during surgery by a homeothermic heating blanket system (Harvard Apparatus, Holliston, MA, USA). Pulse oximetry (model V3304; Waukesha, WI, USA) was used to maintain heart rate at approximately 350 beats per minute with blood oxygen saturation $(\mathrm{SpO} 2)$ levels $>95 \%$.

\subsection{Analysis of infarct volume}

The rats were killed $72 \mathrm{~h}$ post-occlusion with an overdose $(75 \mathrm{mg} / \mathrm{kg}$ ) of Nembutal sodium solution. The brains were carefully removed and placed in chilled saline, and then sliced into 5 serial coronal sections of $2 \mathrm{~mm}$ thickness using a rat brain matrix (Harvard Apparatus) starting at $3 \mathrm{~mm}$ posterior to the anterior pole. After sectioning, the slices were stained with 2\% 2, 3, 5-triphenyltetrazolium chloride (TTC; Sigma Chemical Co.) in saline and kept for 15 min at $37^{\circ} \mathrm{C}$ in the dark. Stained sections were then fixed in $10 \%$ buffered formalin. Both hemispheres of each stained coronal section were scanned using a high-resolution scanner (Epson Perfection 2400 Photo), and then evaluated by digital image analysis (Image Pro System, Media Cybernetics, Silver Spring, MD, USA). The unstained area representing the infarct was integrated across sections and affected hemisphere was expressed as a percentage of the corresponding intact, contralateral structure. These techniques have been used repeatedly in the literature to measure and evaluate stroke outcome in experimental preparations (Bederson et al., 1986; Belayev et al., 1999).

\subsection{Assessment of functional deficits}

The experiment was performed between 9:00 a.m. and 4:00 p.m. The investigator applying the functional tests did not know the identity of the experimental treatment groups until completion of the data analysis.

4.4.1. Rotarod-Motor impairment was assessed using an accelerating rotarod (Columbus Instruments Rotamex 4/8 system, OH, USA, Model 7750). Rotameric tests were performed according to our previous studies (Sayeed et al., 2007). All rats were given 3 training sessions, 10 minutes apart, before surgery to establish baseline performance. Rats were first habituated to the stationary rod, and then exposed to the rotating rod. The rod was started at $4 \mathrm{rpm}$ and accelerated linearly to $30 \mathrm{rpm}$ within $300 \mathrm{sec}$. Latency to fall off the rotarod was then 
determined before ischemia (presurgery) and at 24,48 and $72 \mathrm{~h}$ post-surgery in all rats. The rats were required to stay on the accelerating rod for a minimum of $30 \mathrm{sec}$. If they were unable to reach this criterion, the trial was repeated for a maximum of five times. The two best (largest) fall latency values a rat could achieve were then averaged and used for data analysis. Rats not falling off within 5 min were given a maximum score of 300 seconds

4.4.2. Grip strength-Forelimb grip strength in rats was determined before ischemia and 24,48 and $72 \mathrm{~h}$ after surgery using a grip strength meter (Columbus Instruments, OH, USA). We used an electronic digital force gauge that measured the peak force exerted by the action of the animal while grouping the sensor bar. While being drawn back along a straight line leading away from the sensor, the animal released its grip at some point and the gauge then recorded the maximum force attained at the time of release. The digital reading (in Newtons) of three successive trials were obtained for each rat, averaged and used for data analysis. The pMCAO, vehicle- and PROG-treated rats were tested simultaneously with the shams.

\subsection{Data analysis}

All results were expressed as mean $\pm \mathrm{SD}$ and calculations were obtained using GraphPad Prism and SPSS 11.0 software. Lesion volumes were analyzed using the Student's t-test. Rotarod performance and Grip strength were analyzed by one way analysis of variance (ANOVA), for repeated measures followed by Tukey's test for individual comparisons. Percent difference between pre and post-surgical scores for each animal was used to control for individual differences in Rotorod performance. The criterion for statistical significance was set at $\mathrm{P}<0.05$.

\section{Acknowledgements}

This work was supported by NIH grants R01 NS04851 and Rooms to Go Scholar award. We acknowledge Leslie McCann for her help in manuscript preparation.

\section{References}

Aggarwal R, Medhi B, Pathak A, Dhawan V, Chakrabarti A. Neuroprotective effect of progesterone on acute phase changes induced by partial global cerebral ischaemia in mice. J Pharm Pharmacol 2008;60 (6):731-7. [PubMed: 18498709]

Bederson JB, Pitts LH, Tsuji M, Nishimura MC, Davis RL, Bartkowski H. Rat middle cerebral artery occlusion: evaluation of the model and development of a neurologic examination. Stroke 1986a; 17:472-6. [PubMed: 3715945]

Bederson JB, Pitts LH, Germano SM, Nishimura MC, Davis RL, Bartkowski HM. Evaluation of 2,3,5triphenyltetrazolium chloride as a stain for detection and quantification of experimental cerebral infarction in rats. Stroke 1986b;17:1304-8. [PubMed: 2433817]

Belayev L, Busto R, Zhao W, Fernandez G, Ginsberg MD. Middle cerebral artery occlusion in the mouse by intraluminal suture coated with poly-L-lysine: neurological and histological validation. Brain Res 1999;833:181-90. [PubMed: 10375693]

Betz AL, Coester HC. Effect of steroid therapy on ischaemic brain oedema and blood to brain sodium transport. Acta Neurochir Suppl (Wien) 1990a;51:256-8. [PubMed: 2089910]

Betz AL, Coester HC. Effect of steroids on edema and sodium uptake of the brain during focal ischemia in rats. Stroke 1990b;21:1199-204. [PubMed: 2389301]

Bitran D, Shiekh M, McLeod M. Anxiolytic effect of progesterone is mediated by the neurosteroid allopregnanolone at brain GABAA receptors. J Neuroendocrinol 1995;7:171-177. [PubMed: 7606242]

Bixo M, Backstrom T. Regional distribution of progesterone and 5 $\alpha$-pregnane-3,20-dione in rat brain during progesterone-induced anesthesia. Psychoneuroendocrinology 1990;15:159-162. [PubMed: 2359812] 
Borlongan CV, Chopp M, Steinberg GK, Bliss TM, Li Y, Lu M, Hess DC, Kondziolka D. Potential of stem/progenitor cells in treating stroke: the missing steps in translating cell therapy from laboratory to clinic. Regen Med 2008;3(3):249-50. [PubMed: 18462048]

Cai W, Zhu Y, Furuya K, Li Z, Sokabe M, Chen L. Two different molecular mechanisms underlying progesterone neuroprotection against ischemic brain damage. Neuropharmacology 2008;55:127-38. [PubMed: 18572204]

Cervantes M, Gonzalez-Vidal MD, Ruelas R, Escobar A, Morali G. Neuroprotective effects of progesterone on damage elicited by acute global cerebral ischemia in neurons of the caudate nucleus. Arch Med Res 2002;33:6-14. [PubMed: 11825624]

Chen J, Chopp M, Li Y. Neuroprotective effects of progesterone after transient middle cerebral artery occlusion in rat. J Neurol Sci 1999;171:24-30. [PubMed: 10567046]

Corbett D, Nurse $\mathrm{S}$. The problem of assessing effective neuroprotection in experimental cerebral ischemia. Prog Neurobiol 1998;54:531-48. [PubMed: 9550190]

Cutler SM, Cekic M, Miller DM, Wali B, VanLandingham JW, Stein DG. Progesterone improves acute recovery after traumatic brain injury in the aged rat. J Neurotrauma 2007;24(9):1475-86. [PubMed: 17892409]

Danton GH, Dietrich WD. Inflammatory mechanisms after ischemia and stroke. J Neuropathol Exp Neurol 2003;62:127-36. [PubMed: 12578222]

Delcker A, Diener HC, Timmann D, Faustmann P. The role of vertebral and internal carotid artery disease in the pathogenesis of vertebrobasilar transient ischemic attacks. Eur Arch Psychiatry Clin Neurosci 1993;242:179-83. [PubMed: 8461343]

Djebaili M, Hoffman SW, Stein DG. Allopregnanolone and progesterone decrease cell death and cognitive deficits after a contusion of the rat pre-frontal cortex. Neuroscience 2004;123(2):349-59. [PubMed: 14698743]

Djebaili M, Guo Q, Pettus EH, Hoffman SW, Stein DG. The neurosteroids progesterone and allopregnanolone reduce cell death, gliosis, and functional deficits after traumatic brain injury in rats. J Neurotrauma 2005;22:106-18. [PubMed: 15665606]

Feigin VL. Stroke epidemiology in the developing world. Lancet 2005;365:2160-1. [PubMed: 15978910]

Fisher M. Recommendations for advancing development of acute stroke therapies: Stroke Therapy Academic Industry Roundtable 3. Stroke 2003;34:1539-46. [PubMed: 12750546]

Friess E, Tagaya H, Trachsel L, Holsboer F, Rupprecht R. Progesterone-induced changes in sleep in male subjects. Am J Physiol 1997;272:E885-891. [PubMed: 9176190]

Frydenlund DS, Bhardwaj A, Otsuka T, Mylonakou MN, Yasumura T, Davidson KG, Zeynalov E, Skare O, Laake P, Haug FM, Rash JE, Agre P, Ottersen OP, Amiry-Moghaddam M. Temporary loss of perivascular aquaporin-4 in neocortex after transient middle cerebral artery occlusion in mice. Proc Natl Acad Sci U S A 2006;103:13532-6. [PubMed: 16938871]

Gibson CL, Constantin D, Prior MJ, Bath PM, Murphy SP. Progesterone suppresses the inflammatory response and nitric oxide synthase-2 expression following cerebral ischemia. Exp Neurol 2005;193:522-30. [PubMed: 15869954]

Gibson CL, Murphy SP. Progesterone enhances functional recovery after middle cerebral artery occlusion in male mice. J Cereb Blood Flow Metab 2004;24:805-13. [PubMed: 15241189]

Gilmer LK, Roberts KN, Scheff SW. Efficacy of progesterone following a moderate unilateral cortical contusion injury. J Neurotrauma 2008;25:593-602. [PubMed: 18476780]

Gonzalez-Vidal MD, Cervera-Gaviria M, Ruelas R, Escobar A, Morali G, Cervantes M. Progesterone: protective effects on the cat hippocampal neuronal damage due to acute global cerebral ischemia. Arch Med Res 1998;29:117-24. [PubMed: 9650325]

Goss CW, Hoffman SW, Stein DG. Behavioral effects and anatomic correlates after brain injury: a progesterone dose-response study. Pharmacol Biochem Behav 2003;76:231-42. [PubMed: 14592674]

Guo Q, Sayeed I, Baronne LM, Hoffman SW, Guennoun R, Stein DG. Progesterone administration modulates AQP4 expression and edema after traumatic brain injury in male rats. Exp Neurol 2006;198:469-78. [PubMed: 16445913] 
Hacke W, Schwab S, Horn M, Spranger M, De Georgia M, von Kummer R. 'Malignant' middle cerebral artery territory infarction: clinical course and prognostic signs. Arch Neurol 1996;53:309-15. [PubMed: 8929152]

Hankey GJ. Stroke: how large a public health problem, and how can the neurologist help? Arch Neurol 1999;56:748-54. [PubMed: 10369318]

Hattori K, Lee H, Hurn PD, Crain BJ, Traystman RJ, DeVries AC. Cognitive deficits after focal cerebral ischemia in mice. Stroke 2000;31:1939-44. [PubMed: 10926961]

He J, Evans CO, Hoffman SW, Oyesiku NM, Stein DG. Progesterone and allopregnanolone reduce inflammatory cytokines after traumatic brain injury. Exp Neurol 2004;189:404-12. [PubMed: 15380490]

Hunter AJ, Mackay KB, Rogers DC. To what extent have functional studies of ischaemia in animals been useful in the assessment of potential neuroprotective agents? Trends Pharmacol Sci 1998;19:59-66. [PubMed: 9550943]

Jiang N, Chopp M, Stein D, Feit H. Progesterone is neuroprotective after transient middle cerebral artery occlusion in male rats. Brain Res 1996;735:101-7. [PubMed: 8905174]

Kassem-Moussa H, Graffagnino C. Nonocclusion and spontaneous recanalization rates in acute ischemic stroke: a review of cerebral angiography studies. Arch Neurol 2002;59:1870-3. [PubMed: 12470173]

Kitagawa K, Matsumoto M, Yang G, Mabuchi T, Yagita Y, Hori M, Yanagihara T. Cerebral ischemia after bilateral carotid artery occlusion and intraluminal suture occlusion in mice: evaluation of the patency of the posterior communicating artery. J Cereb Blood Flow Metab 1998;18:570-9. [PubMed: 9591849]

Kumon Y, Kim SC, Tompkins P, Stevens A, Sakaki S, Loftus CM. Neuroprotective effect of postischemic administration of progesterone in spontaneously hypertensive rats with focal cerebral ischemia. J Neurosurg 2000;92:848-52. [PubMed: 10794300]

Luconi M, Bonaccorsi L, Maggi M, Pecchioli P, Krausz C, Forti G, Baldi E. Identification and characterization of functional nongenomic progesterone receptors on human sperm membrane. J Clin Endocrinol Metab 1998;83:877-85. [PubMed: 9506743]

Majewska MD. Neurosteroids: endogenous bimodal modulators of the GABAA receptor. Mechanism of action and physiological significance. Prog Neurobiol 1992;38:379-95. [PubMed: 1349441]

Mani SK. Signaling mechanisms in progesterone-neurotransmitter interactions. Neuroscience 2006;138:773-81. [PubMed: 16310962]

Memezawa H, Zhao Q, Smith ML, Siesjo BK. Hyperthermia nullifies the ameliorating effect of dizocilpine maleate (MK-801) in focal cerebral ischemia. Brain Res 1995;670:48-52. [PubMed: 7719723]

Mergenthaler P, Dirnagl U, Meisel A. Pathophysiology of stroke: lessons from animal models. Metab Brain Dis 2004;19:151-67. [PubMed: 15554412]

Merryman W, Boiman R, Barnes L, Rothchild I. Progesterone anesthesia in human subjects. J Clin Endocrinol Metab 1959;14:1567-1569. [PubMed: 13211793]

Muntner P, Garrett E, Klag MJ, Coresh J. Trends in stroke prevalence between 1973 and 1991 in the US population 25 to 74 years of age. Stroke 2002;33:1209-13. [PubMed: 11988592]

Murphy SJ, Littleton-Kearney MT, Hurn PD. Progesterone administration during reperfusion, but not preischemia alone, reduces injury in ovariectomized rats. J Cereb Blood Flow Metab 2002;22:11818. [PubMed: 12368656]

Reddy DS, Kulkarni SK. Differential anxiolytic effects of neurosteroids in the mirrored chamber behavior test in mice. Brain Res 1997;752:61-71. [PubMed: 9106441]

Reglodi D, Somogyvari-Vigh A, Maderdrut JL, Vigh S, Arimura A. Postischemic spontaneous hyperthermia and its effects in middle cerebral artery occlusion in the rat. Exp Neurol 2000;163:399407. [PubMed: 10833314]

Reglodi D, Tamas A, Lengvari I. Examination of sensorimotor performance following middle cerebral artery occlusion in rats. Brain Res Bull 2003;59:459-66. [PubMed: 12576143]

Roof RL, Duvdevani R, Stein DG. Gender influences outcome of brain injury: progesterone plays a protective role. Brain Res 1993;607:333-6. [PubMed: 8481809]

Roof RL, Hoffman SW, Stein DG. Progesterone protects against lipid peroxidation following traumatic brain injury in rats. Mol Chem Neuropathol 1997;31:1-11. [PubMed: 9271001] 
Sayeed I, Guo Q, Hoffman SW, Stein DG. Allopregnanolone, a progesterone metabolite, is more effective than progesterone in reducing cortical infarct volume after transient middle cerebral artery occlusion. Ann Emerg Med 2006;47:381-9. [PubMed: 16546625]

Sayeed I, Wali B, Stein DG. Progesterone inhibits ischemic brain injury in a rat model of permanent middle cerebral artery occlusion. Restor Neurol Neurosci 2007;25:151-9. [PubMed: 17726274]

Smith SS, Woolley CS. Cellular and molecular effects of steroid hormones on CNS excitability. Cleve Clin J Med 2004;71:S4-10. [PubMed: 15379294]

Stein DG. Progesterone exerts neuroprotective effects after brain injury. Brain Res Rev 2008 Mar;57(2): 386-97. [PubMed: 17826842]

Stein, DG.; Hurn, PD. Effects of Sex Steroids on Damaged Neural Systems. In: Pfaff, D., et al., editors. Hormones, Brain and Behavior. Vol. 2nd. Vol. IV. Elsevier; in press

Tamura A, Graham DI, McCulloch J, Teasdale GM. Focal cerebral ischaemia in the rat: 1. Description of technique and early neuropathological consequences following middle cerebral artery occlusion. J Cereb Blood Flow Metab 1981;1:53-60. [PubMed: 7328138]

VanLandingham JW, Cekic M, Cutler S, Hoffman SW, Stein DG. Neurosteroids reduce inflammation after TBI through CD55 induction. Neurosci Lett 2007;425(2):94-8. [PubMed: 17826908]

VanLandingham JW, Cutler SM, Virmani S, Hoffman SW, Covey DF, Krishnan K, Hammes SR, Jamnongjit M, Stein DG. The enantiomer of progesterone acts as a molecular neuroprotectant after traumatic brain injury. Neuropharmacology 2006;51:1078-85. [PubMed: 16926035]

Wahl F, Allix M, Plotkine M, Boulu RG. Neurological and behavioral outcomes of focal cerebral ischemia in rats. Stroke 1992;23:267-72. [PubMed: 1561657]

Wright DW, Bauer ME, Hoffman SW, Stein DG. Serum progesterone levels correlate with decreased cerebral edema after traumatic brain injury in male rats. J Neurotrauma 2001;18:901-9. [PubMed: 11565602]

Wright DW, Kellermann AL, Hertzberg VS, Clark PL, Frankel M, Goldstein FC, Salomone JP, Dent LL, Harris OA, Ander DS, Lowery DW, Patel MM, Denson DD, Gordon AB, Wald MM, Gupta S, Hoffman SW, Stein DG. ProTECT: a randomized clinical trial of progesterone for acute traumatic brain injury. Ann Emerg Med 2007;49:391-402. 402-e1-2. [PubMed: 17011666]

Xiao G, Wei J, Yan W, Wang W, Lu Z. Improved outcomes from the administration of progesterone for patients with acute severe traumatic brain injury: a randomized controlled trial. Crit Care 2008;12:R61. [PubMed: 18447940]

Yamamoto M, Tamura A, Kirino T, Shimizu M, Sano K. Behavioral changes after focal cerebral ischemia by left middle cerebral artery occlusion in rats. Brain Res 1988;452:323-8. [PubMed: 3401738]

Zhao Q, Memezawa H, Smith ML, Siesjo BK. Hyperthermia complicates middle cerebral artery occlusion induced by an intraluminal filament. Brain Res 1994;649:253-9. [PubMed: 7953639] 
A
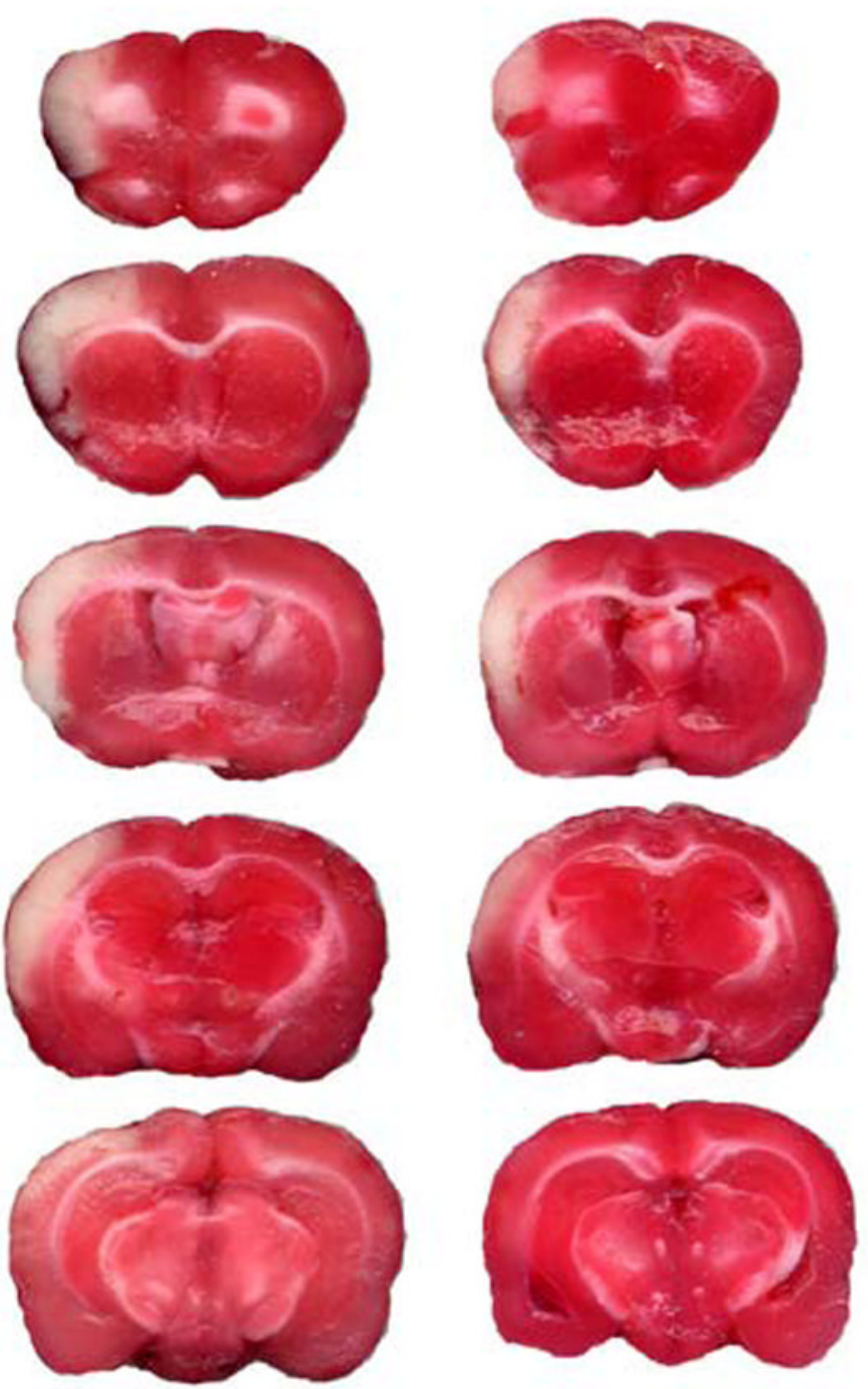

\section{PMCAO $\quad$ MMCAO + PROG}




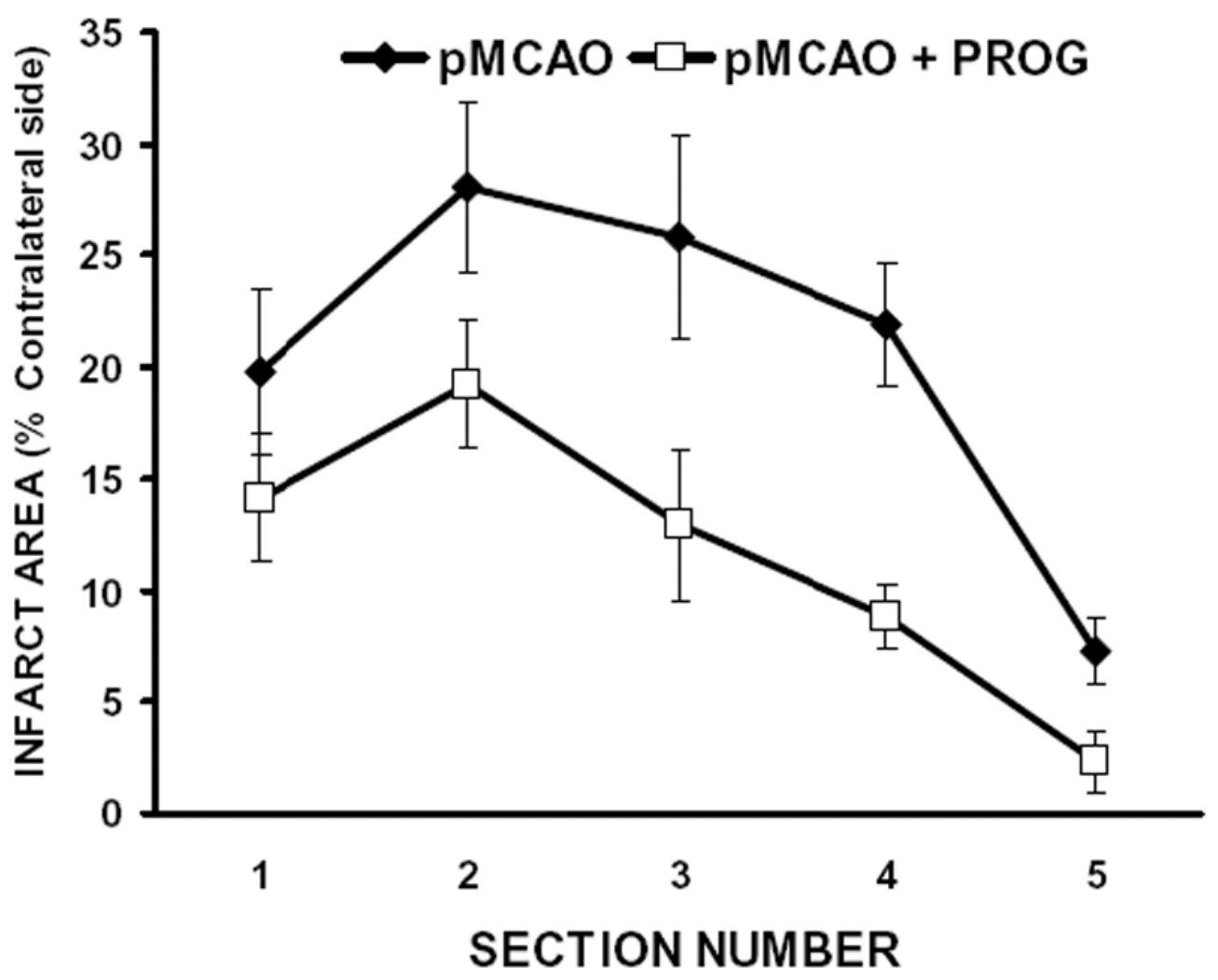

Figure 1. PROG reduces infarct volume in a rat model of pMCAO

A) TTC-stained coronal sections from representative rats given either vehicle or PROG, brains harvested at $72 \mathrm{~h}$ post occlusion. Infarcts are shown as pale (unstained) regions. The infarct area in PROG-treated rats is substantially reduced. B) Line graph shows the percent area distribution of infarction to the area of the contralateral side in each of five forebrain sections in $\mathrm{pMCAO}$ and $\mathrm{pMCAO}$ plus PROG treated groups. Values are mean $\pm \mathrm{SD}$. 


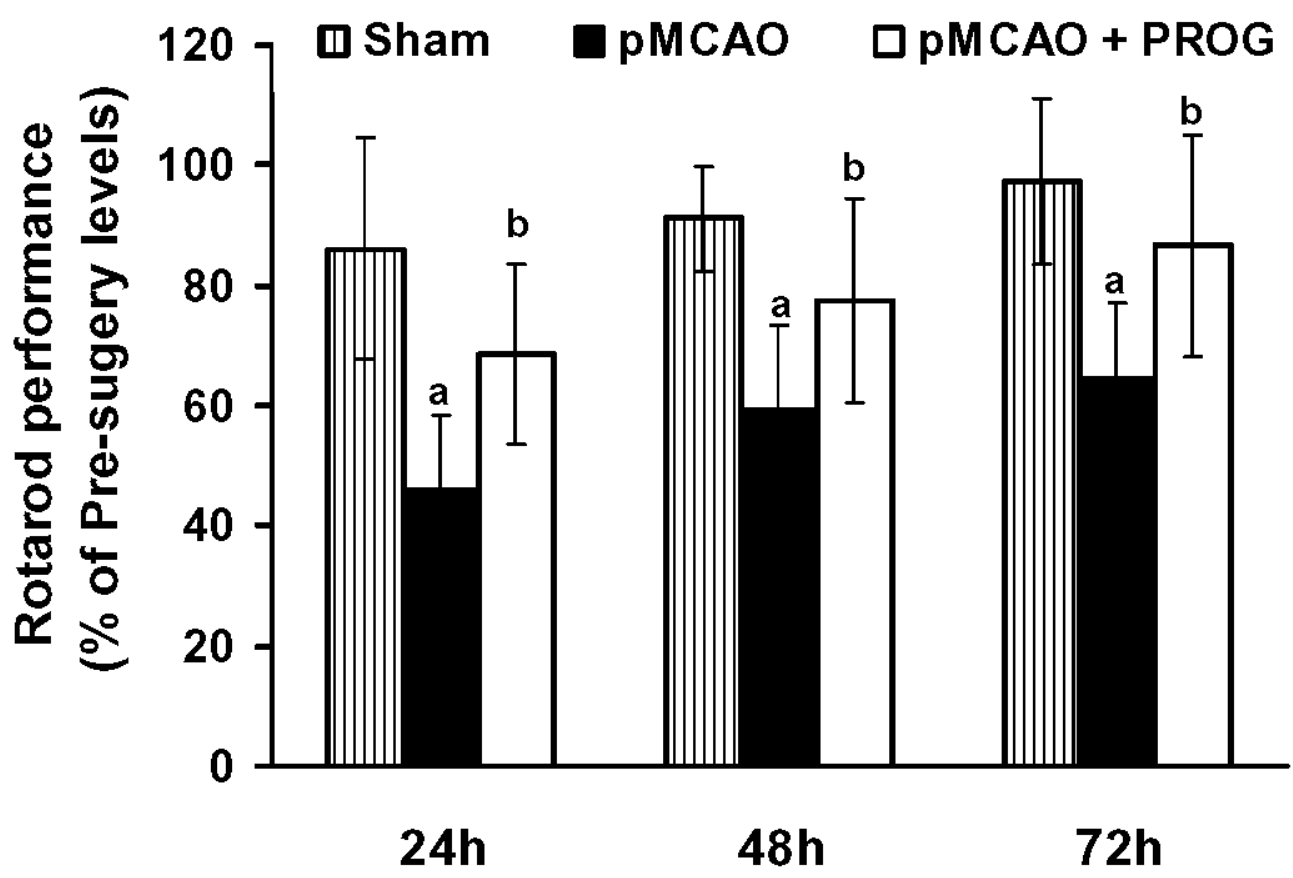

Figure 2. PROG reduces motor impairment following pMCAO

Motor ability as assessed using the rotarod. The rotometric performance significantly $(\mathrm{P}<0.05)$ decreased in rats subjected to pMCAO plus vehicle treated compared to sham-operated plus vehicle. PROG-treated rats were less impaired than vehicle-treated rats at all time points (24, $48,72 \mathrm{~h}$ post-injury). They were able to remain on the rotarod for a significantly $(\mathrm{P}<0.05)$ greater amount of time ( $\mathrm{P}<0.05$ compared with pre-surgery values). Time spent on the rotarod is expressed as a percentage of pre-surgery control value as percentage mean $\pm \mathrm{SD}$. $[(\mathrm{P}<$ $0.05)^{\mathrm{a}}=$ significant difference compared to Sham + Vehicle $v s$. pMCAO + Vehicle; $(\mathrm{P}<$ $0.05)^{b}=$ significant difference compared to pMCAO + Vehicle $v s$. pMCAO + PROG]. 


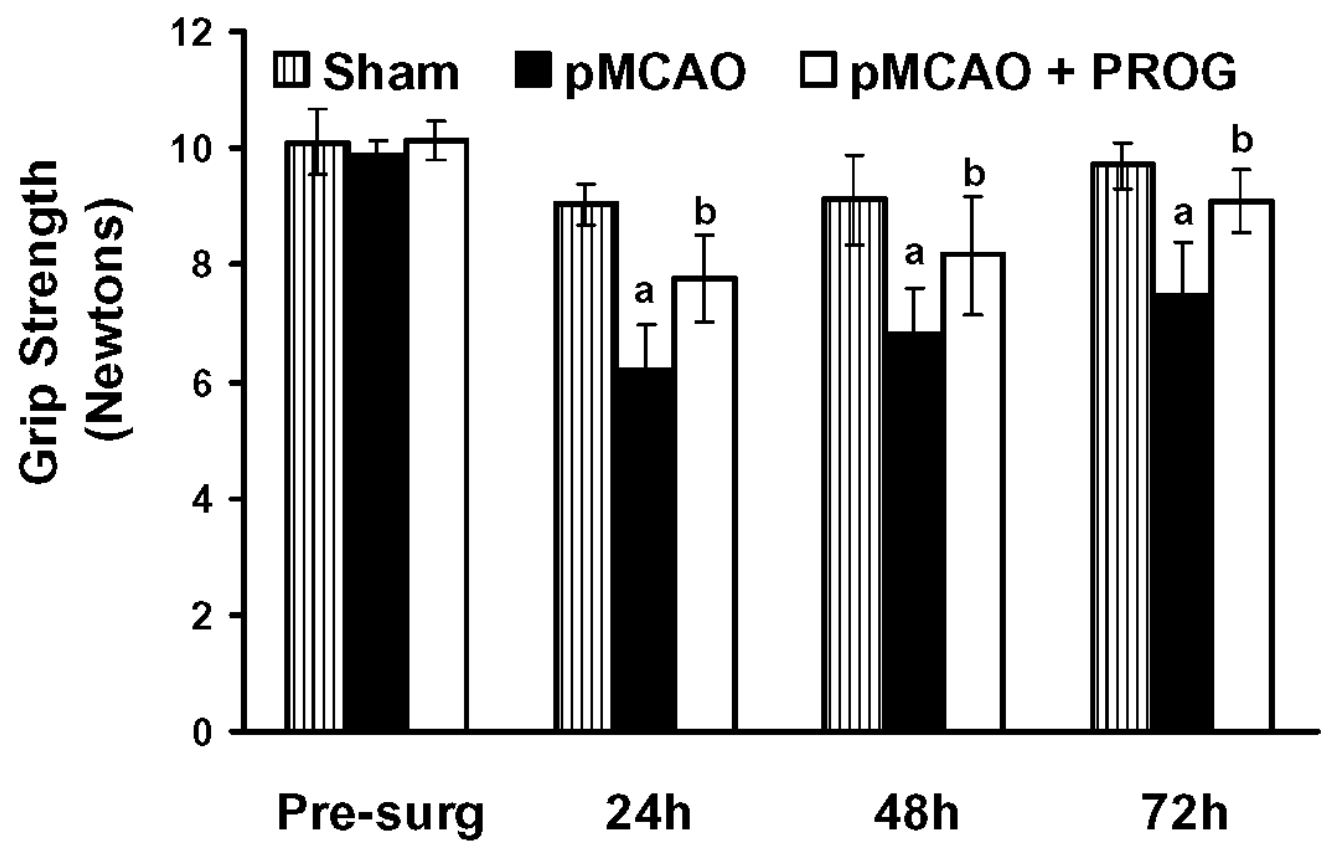

Figure 3. PROG improves grip strength in rat model of pMCAO

Values are expressed as mean \pm SD. The rats subjected to pMCAO + vehicle showed significantly $(\mathrm{P}<0.05)$ lower grip strength scores at all time points as compared to sham + vehicle rats. PROG-treated rats showed significantly $(\mathrm{P}<0.05)$ improved average scores at all time points $(24,48,72 \mathrm{~h}$ post-injury) compared to pMCAO plus vehicle-treated animals. [(P $<0.05)^{\mathrm{a}}=$ significant difference compared to Sham + Vehicle $v s$. pMCAO + Vehicle; $(\mathrm{P}<$ $0.05)^{b}=$ significant difference compared to pMCAO + Vehicle vs. pMCAO + PROG]. 


\section{Physiological Monitor}

\section{Table 1}

\begin{tabular}{|l|l|l|l|}
\hline Group & SpO2 & Heart beats & Temperature \\
\hline \multirow{2}{*}{ Sham } & $95.21 \pm 2.87$ & $354.42 \pm 6.52$ & $36.95 \pm 1.34$ \\
\cline { 2 - 4 } & $\mathbf{9 5 . 2 0} \pm \mathbf{2 . 8 6}$ & $\mathbf{3 5 2 . 7 8} \pm \mathbf{6 . 5 4}$ & $\mathbf{3 7 . 0 0} \pm \mathbf{2 . 2 8}$ \\
\hline \multirow{2}{*}{ pMCAO } & $96.0 \pm 3.75$ & $350.45 \pm 5.42$ & $37.03 \pm 2.21$ \\
\cline { 2 - 4 } & $\mathbf{9 4 . 5 4} \pm \mathbf{2 . 9 5}$ & $\mathbf{3 5 4 . 7 4} \pm \mathbf{4 . 8 9}$ & $\mathbf{3 6 . 5 9} \pm \mathbf{1 . 3 1}$ \\
\hline \multirow{2}{*}{ pMCAO + PROG } & $95.45 \pm 2.46$ & $356.16 \pm 8.38$ & $36.78 \pm 2.40$ \\
\cline { 2 - 4 } & $\mathbf{9 5 . 1 2} \pm \mathbf{1 . 9 8}$ & $\mathbf{3 5 5 . 2 5} \pm \mathbf{5 . 0 2}$ & $\mathbf{3 6 . 8 9} \pm \mathbf{1 . 4 4}$ \\
\hline \multicolumn{2}{|c|}{10 minutes before occlusion; 90 minutes after occlusion } \\
\hline
\end{tabular}

Values are expressed as mean $\pm \mathrm{SD}$. The physiological parameters (blood SpO2, heart beats and temperature) were monitored at 10 minutes before and 90 minutes after occlusion. There were no significant differences among the groups for these parameters. 